\title{
ESTIMACIÓN DE LAS VARIACIONES ESPACIO TEMPORALES DE ALBEDO EN LOS GLACIARES OLIVARES, CHILE CENTRAL
}

\author{
ESTIMATING SPATIOTEMPORAL VARIATIONS OF ALBEDO IN THE OLIVARES \\ GLACIERS, CENTRAL CHILE
}

\author{
Sr. Marco A. Peña ${ }^{1}$ y Sr. Fabián Olmedo²
}

\section{RESUMEN}

Este estudio derivó mediciones de albedo en los glaciares Olivares Alfa, Beta y Gama, ubicados en Los Andes de Chile central, mediante el procesamiento de imágenes satelitales Landsat adquiridas en Enero de 1990, 1996 y 2017, con el propósito de estimar las variaciones espaciales y temporales de dicha variable. Entre 1990 y 2017 , el albedo promedio del glaciar Olivares Alfa se redujo en $0,17(0,43-0,26)$, lo que se tradujo en una tasa de retroceso anual de 1,78\%. Durante el mismo período, el albedo promedio del glaciar Olivares Beta se redujo en $0,09(0,48-0,39)$, lo que se tradujo en una tasa de retroceso anual de $1,33 \%$, en tanto que el albedo promedio del glaciar Olivares Gama se redujo en 0,12 (0,45-0,33), traduciéndose en una tasa de retroceso anual de 1,1\%. El mapeo del diferencial de albedo de cada glaciar, resultante de restar el albedo de 1990 al de 2017, permitió apreciar las variaciones espaciales de la variable durante dicho período, evidenciando sus mayores decrecimientos tanto en las zonas de acumulación como de ablación de los glaciares. El cálculo remoto de albedo podría incluirse en los balances de masa de estos y otros glaciares del país, a fin de dimensionar el impacto de la reducción de esta variable en la pérdida de hielo y su relación con la variabilidad climática inducida por el calentamiento y cambio climático global.

Palabras clave: Albedo. Landsat. Glaciares. Albedo planetario. Teledetección.

\section{ABSTRACT}

This study derived albedo measurements from the Olivares Alfa, Beta and Gama glaciers, placed on the central Chilean Andes, by processing Landsat-8 satellite images acquired in January 1990, 1996 and 2017. The aim was to estimate spatiotemporal variations of such a variable. Between 1990 and 2017, the average albedo of the Olivares Alfa glacier decreased by $0.17(0.43-0.26)$, which translated into an annual rate of decrease of $1.78 \%$. On the same period, the average albedo of Olivares Beta glacier decreased by $0.09(0.48-0.39)$, which translated into an annual rate of decrease of $1.33 \%$, while the average albedo of the Olivares Gama glacier decreased by $0.12(0.45-0.33)$, translating into an annual rate of decrease of $1.1 \%$. The mapping of the albedo differential of each glacier, resulting from subtracting the 1990 albedo from the 2017 albedo, enabled to appreciate the spatial variations of the variable, which evidenced its largest decreases on both, accumulation and ablation glacier zones. The remote sensing-derived albedo could be included in the mass balance of these and other glaciers of the country. This would enable to assess the impact of the decreasing of this variable on the ice loss and its relationship with the climatic variability induced by the global warming and climate change.

Keywords: Albedo. Landsat. Glaciers. Planetary albedo. Remote sensing.

\footnotetext{
${ }^{1}$ Departamento de Geografía, Universidad Alberto Hurtado. Cienfuegos 41, Santiago, Chile

${ }^{2}$ Departamento de Geografía, Universidad Alberto Hurtado. Cienfuegos 41, Santiago, Chile
}

Fecha de Recepción: 12 de junio de 2019

Fecha de Aprobación: 20 de diciembre de 2019 


\section{INTRODUCCIÓN}

El concepto de albedo alude a la fracción de radiación solar incidente en una superficie que es reflejada de vuelta al espacio. Tal radiación está compuesta de longitudes de onda pertenecientes a las dimensiones espectrales ultravioleta $(0,3-0,4$ $\mu \mathrm{m}, 7 \%)$, visible $(0,4-0,7 \mu \mathrm{m}, 43 \%)$ e infrarroja de onda corta $(0,7-3 \mu \mathrm{m}, 49 \%)$. En promedio, la radiación solar que ingresa a la Tierra o irradiancia exoatmosférica, es de $340 \mathrm{w} / \mathrm{m}^{2}$, siendo el $~ 30 \%$ de ésta $\left(\sim 100 \mathrm{w} / \mathrm{m}^{2}\right)$ reflejada por su superficie y atmósfera, monto que define el albedo promedio de nuestro planeta (NASA 2014; Stephens et al., 2015).

El albedo es una variable crítica en el balance energético de la Tierra, por cuanto determina el monto de radiación disponible para ser emitida (calor) por ésta, incidiendo con ello, en su estabilidad térmica (Stephens et al., 2015). Las crecientes emisiones antrópicas de dióxido de carbono y vapor de agua principalmente, han tenido por efecto reforzar el efecto invernadero del planeta, debido a la capacidad de estas moléculas de absorber radiación, reteniéndola como calor en el sistema Tierra e incrementando subsecuentemente, su temperatura (Strahler, 2013). El calentamiento anómalo del planeta ha favorecido a su vez el incremento de la temperatura atmosférica planetaria y el consecuente derretimiento de las masas de hielo, caracterizadas por una alta reflectividad. Esto último, ha propiciado la reducción del albedo planetario, haciendo que más radiación solar quede disponible para ser emitida, retroalimentado positivamente el calentamiento global (NASA, 2007; Stephens et al., 2015; Strahler, 2013). Se estima que un cambio de $5 \%$ en el albedo planetario equivale a un cambio de $1^{\circ} \mathrm{C}$ en la temperatura superficial global, lo cual aumentaría hasta alrededor de un metro el nivel medio de los océanos a causa del derretimiento del hielo (Church et al., 2013). A su vez, se estima que la temperatura media anual para el año 2100 podría aumentar un mínimo de $1,4^{\circ} \mathrm{C}$ y un máximo de $5,6^{\circ} \mathrm{C}$ a causa del calentamiento global, lo que implicaría un ascenso del nivel medio de los océanos suficiente como para cubrir numerosas tierras bajas habitadas a lo largo del planeta (Nieto, 2018).
La disminución del albedo planetario hoy reviste de gran preocupación en el contexto del estudio del cambio climático global, siendo la criósfera uno de los principales componentes terrestres monitoreados, debido a las evidencias 35 ue sustentan su acelerada tendencia a la reducción por derretimiento y recubrimiento, como consecuencia del calentamiento global (Strahler, 2013; Stephens et al., 2015). En este contexto, las imágenes satelitales ópticas son de principal aporte, por cuanto proveen una visión sinóptica y temporalmente regular de las masas de hielo del planeta. Hoy, numerosas misiones satelitales con fines de observación terrestre, proveen imágenes ópticas de la Tierra que cuentan con registros de reflectividad a lo largo de todo el espectro solar (bandas espectrales), permitiendo con ello, calcular el albedo de la superficie retratada. Tratándose el albedo de una medida integrada de reflectividad a lo largo del espectro solar, la suma ponderada de las bandas de una imagen óptica de acuerdo al aporte de sus irradiancias espectrales equivalentes en la irradiancia superficial total, constituye una forma relativamente simple y fiable de cálculo de esta variable (Liang, 2000; Liang et al., 2012).

El análisis de imágenes CERES (Clouds and the Earth's Radiant Energy System) adquiridas entre los años 2000 y 2011 ha permitido concluir que, si bien el albedo planetario muestra fluctuaciones cíclicas que impiden afirmar que exhibe una tendencia decreciente, los albedos de los hielos continentales Ártico y Antártico sí evidencian tal tendencia con más claridad, tanto espacial como temporalmente (NASA, 2014). A este respecto, Pistone et al. (2014) estimaron mediante imágenes CERES adquiridas entre 1979 y 2011, un decrecimiento del albedo del hielo Ártico de 52 a $48 \%$. También los glaciares de montaña muestran albedos decrecientes, como ha sido constatado en Los Alpes mediante imágenes MODIS (Moderate Resolution Imaging Spectroradiometer) entre los años 2000 y 2015, siendo las zonas de ablación y acumulación de los glaciares aquellas que han mostrado el mayor descenso de la variable (Di Mauro et al., 2016). En la región del Himalaya en tanto, imágenes MODIS adquiridas entre 2000 y 2011 también confirman la disminución del albedo de sus glaciares, acentuándose particularmente sobre los $6.000 \mathrm{msnm}$, lo que implicaría una extensión del derretimiento de hielo hacia las zonas de acumulación de los glaciares (Ming et al., 2015). 
El estudio del albedo glaciar cobra principal relevancia para Chile, considerando que concentra el $82 \%$ de los glaciares del continente (Leiva, 2014). Si bien el albedo ha sido medido de manera in situ en diferentes glaciares de Los Andes semiáridos chilenos, como el Tapado (Lhermitte et al., 2013), Toro 1 y Guanaco (Abermann et al., 2014), aún no existen estudios que tomando ventaja de la naturaleza espacialmente sinóptica y temporalmente repetitiva que brindan las imágenes óptico-satelitales, hayan monitoreado el comportamiento espacio-temporal de esta variable. Ello comportaría un aporte en los estudios de balance de masa glaciar, particularmente aquellos insertos en cuencas de alto valor económico y social como ocurre en zona central del país. El presente trabajo se enmarca dentro de un estudio piloto dirigido a estimar variaciones espaciotemporales de albedo derivado de imágenes óptico-satelitales en los glaciares Olivares Alfa, Beta y Gama, ubicados en Los Andes de Chile central y de vital importancia para el abastecimiento de agua de sus valles. Con esto, se pretende dar primeras pistas acerca de cómo ha evolucionado el albedo de los glaciares de la zona en el contexto de la variabilidad climática y su posible vinculación con el calentamiento y cambio climático global.

\section{MÉTODOS}

\section{ÁREA DE ESTUDIO}

El área de estudio está conformada por los glaciares Olivares Alfa $\left(33^{\circ} 11^{\prime} 25^{\prime \prime} \mathrm{S}-70^{\circ} 13^{\prime} 15^{\prime \prime} \mathrm{O}\right)$,

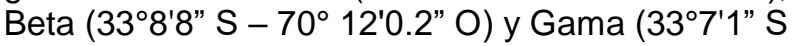
- 70॰10'34" O) (Figura 1), emplazados en las nacientes de la cuenca del Río Olivares, cuyo exutorio es tributario del Río Colorado, que a su vez forma parte de la cuenca del Río Maipo, inserta en la Región Metropolitana de Chile. Los glaciares en su conjunto cubren una superficie de $47,61 \mathrm{~km}^{2}$ con elevaciones que van desde los 3.600 a los 5.300 msnm, aproximadamente. La cuenca del Río Maipo se inserta en un Clima Mediterráneo Semiárido, con precipitaciones que se concentran principalmente en invierno y temperaturas máximas concentradas en verano. En el área de estudio específicamente, el clima propio de alta montaña se caracteriza por inviernos largos y fríos con temperaturas del orden de $4^{\circ} \mathrm{C}$ en los meses invernales y de $15^{\circ} \mathrm{C}$ en los meses de verano. La precipitación es casi exclusivamente sólida alcanzando los $400 \mathrm{~mm}$ en años regulares (DGA, 2018).

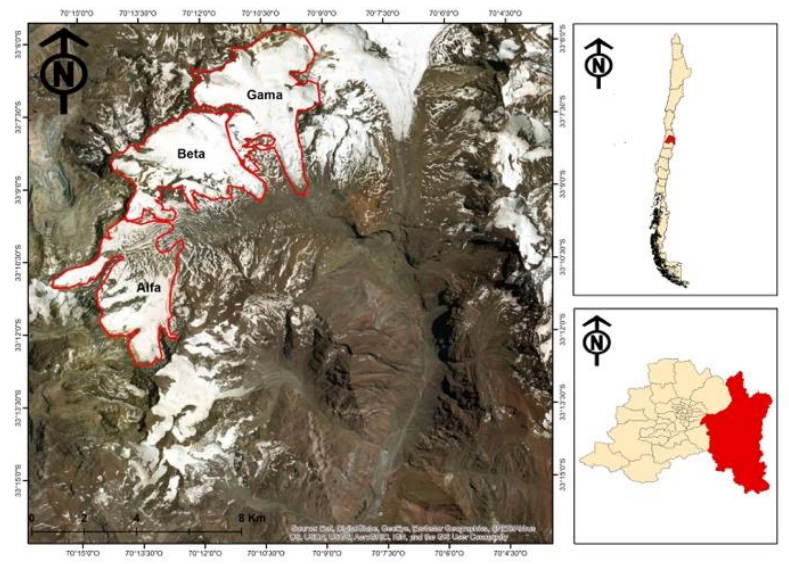

\section{SELECCIÓN DE AÑOS DE ESTUDIO}

El presente estudio se basó en la comparación interanual del albedo calculado en los glaciares de interés a partir de imágenes Landsat libres de

Figura 1. Localización de los Glaciares Olivares Alfa, Beta y Gama.

nubosidad. Sin embargo, debido a las anomalías climáticas que introducen los fenómenos de El Niño y La Niña en las variables climáticas e hidrológicas de zonas latitudinales como en las que se inserta nuestra área de estudio, los años potencialmente elegibles para el cálculo de dicha variable se vieron fuertemente reducidos. Para descartar estos años dentro del período de interés se observaron los índices climáticos del Niño y la Niña, provistos por el Climate Prediction Center (2018). Este índice considera que una desviación de al menos $0,5^{\circ} \mathrm{C}$ del promedio de temperatura superficial del Océano Pacífico durante más de tres meses corresponde a un año Niño (aumento en la intensidad de la alta presión) o Niña (descenso en la intensidad de la alta presión).

Por otra parte, dado que el albedo de un glaciar puede experimentar importantes incrementos transitorios a causa de la cobertura nival estacional, sólo imágenes adquiridas durante el mes más seco del año en el área de estudio, i.e. Enero, fueron potencialmente elegibles. Finalmente, dado que el presente estudio busca develar tendencias temporales en el albedo de los glaciares de interés a lo largo de las últimas décadas, se evitó seleccionar imágenes adquiridas en años consecutivos que pudieran significar una redundancia de datos. Considerando los criterios mencionados, sólo tres imágenes, adquiridas en 
Enero de 1990, 1996 y 2017, pudieron ser seleccionadas.

\section{DESCARGA DE IMÁGENES SATELITALES}

Las tres imágenes Landsat de interés fueron seleccionadas y descargadas gratuitamente desde el portal Global Visualization Viewer (http://glovis.usgs.gov) del USGS (United States Geological Survey). Las imágenes son distribuidas con un sistema de proyección cartográfica UTM (Universal Transversal de Mercator), de modo que no requieren correcciones geométricas adicionales para los propósitos de este estudio. Debido a que el estudio se enfoca en el cálculo del albedo, las bandas termales o de onda larga de estas imágenes fueron descartadas. En el caso de la imagen Landsat-8 (2017), adicionalmente fue descartada la banda pancromática (8), así como las bandas 1 y 9 , que se relacionan con la detección de aerosoles y cirros, respectivamente, ambas prescindibles para el cálculo de albedo. En cuanto al procesamiento radiométrico de las imágenes, sus números digitales fueron convertidos a radiancias absolutas y éstas a reflectancias superficiales empleando el software ENVIC (Environment for Visualizing Images) 5.3. Las principales características técnicas de las imágenes empleadas son presentadas en la Tabla 1.

\begin{tabular}{|c|c|c|c|c|}
\hline \multicolumn{2}{|c|}{ Imagen } & \multicolumn{2}{|c|}{ Resolución espectral } & \multirow[b]{2}{*}{$\begin{array}{l}\text { Resolución } \\
\text { espacial } \\
\text { (m) }\end{array}$} \\
\hline $\begin{array}{l}\text { Fecha de } \\
\text { adquisición }\end{array}$ & $\begin{array}{l}\text { Satélite } \\
\text {-sensor }\end{array}$ & \#Banda & $\begin{array}{l}\text { Longitud } \\
\text { de onda } \\
(\mu \mathrm{m})\end{array}$ & \\
\hline $\begin{array}{c}15 \mathrm{de} \\
\text { Enero de } \\
1990 \mathrm{y}\end{array}$ & $\begin{array}{c}\text { Landsat } \\
4 \text {-TM }\end{array}$ & $\begin{array}{c}\text { 1- Azul } \\
2 \text { - Verde } \\
3 \text { - Rojo } \\
4 \text { - Infrarrojo cercano }\end{array}$ & $\begin{array}{l}0,45-0,52 \\
0,52-0,60 \\
0,63-0,69 \\
0,76-0,90\end{array}$ & \multirow{4}{*}{30} \\
\hline $\begin{array}{c}17 \text { de } \\
\text { Enero de } \\
1996\end{array}$ & $\begin{array}{c}\text { Landsat } \\
5-\mathrm{TM}\end{array}$ & $\begin{array}{c}5 \text { - Infrarrojo de onda } \\
\text { corta } 1 \\
7 \text { - Infrarrojo de onda } \\
\text { corta } 2\end{array}$ & $\begin{array}{l}1,55-1,75 \\
2,08-2,35\end{array}$ & \\
\hline \multirow{2}{*}{$\begin{array}{c}17 \text { de } \\
\text { Enero de } \\
2017\end{array}$} & \multirow{2}{*}{$\begin{array}{c}\text { Landsat } \\
8 \text {-OLI }\end{array}$} & $\begin{array}{c}2 \text { - Azul } \\
3 \text { - Verde } \\
4 \text { - Rojo } \\
5 \text { - Infrarrojo cercano }\end{array}$ & $\begin{array}{l}0,45-0,51 \\
0,53-0,59 \\
0,63-0,67 \\
0,85-0,88\end{array}$ & \\
\hline & & $\begin{array}{c}6 \text { - Infrarrojo de onda } \\
\text { corta } 1 \\
7 \text { - Infrarrojo de onda } \\
\text { corta } 2\end{array}$ & $\begin{array}{l}1,56-1,65 \\
2,1-2,29\end{array}$ & \\
\hline
\end{tabular}

Tabla 1. Principales características técnicas de las imágenes empleadas en este estudio.

CÁLCULO DE ALBEDO
Los tres glaciares de interés fueron delimitados en la forma de polígonos sobre una imagen satelital Landsat-4, adquirida en Enero de 1989. Esto permitió recortar el área cubierta por los glaciares sobre cada una de las tres imágenes sobre la base de su límite más antiguo, para luego proceder a calcular el albedo de éstos. El empleo de un modelo digital de elevación ASTER (Advanced Spaceborne Thermal Emission and Reflection Radiometer) permitió trazar el límite entre las zonas de acumulación y ablación de cada glaciar, cuya referencia altitudinal fue tomada del inventario de glaciares de la DGA (Dirección General de Aguas, 2018).

El albedo se calculó mediante la fórmula propuesta por Liang (2001) para las imágenes Landsat, que básicamente propone una suma ponderada de bandas ópticas en atención al peso que tienen sus irradiancias superficiales equivalentes en el albedo medido en diversos tipos de superficie y bajo diversas condiciones atmosféricas y de iluminación.

$$
\begin{aligned}
& \alpha=0,356_{\alpha 1}+0,130_{\alpha 3}+0,373_{\alpha 4}+0,085_{\alpha 5}+0,072_{\alpha 7}- \\
& 0,0018
\end{aligned}
$$

Donde, $\alpha_{n}$ corresponde a la reflectividad superficial de una banda $n$ Landsat, multiplicada por su respectivo coeficiente de conversión, derivado de su modelamiento empírico para un amplio rango de materiales y condiciones de iluminación.

\section{DIFERENCIALES DE ALBEDO}

Una vez obtenidos los cálculos de albedo para cada glaciar, se realizaron tres sustracciones entre pares de imágenes, con el fin de dilucidar los descensos (o incrementos) experimentados por el albedo de cada glaciar de interés, y sus respectivas zonas de acumulación y ablación, en los períodos 19901996, 1996-2017 y 1990-2017.

Para cada glaciar fueron obtenidos histogramas que mostraron las frecuencias de valores de albedo en los años de interés. Adicionalmente, fue calculada la tasa de decrecimiento del albedo de cada glaciar según período de interés, empleando la siguiente fórmula:

$$
\left(\left(\alpha_{f} / \alpha_{i}\right)^{1 / n}-1\right) \times 100
$$

Donde, $\alpha_{\mathrm{f}}$ y $\alpha_{\mathrm{i}}$ son los promedios de albedo para los años final e inicial de un período, respectivamente, y $n$ es el número de años del período. 
Con el sentido de sintetizar la presentación de resultados, sólo el diferencial de albedo del período 1990-2017 fue mapeado para cada glaciar, agrupando sus valores en tres clases definidas a partir del criterio de terciles. Con el fin de favorecer la interpretación de dichos mapas, todas aquellas superficies que experimentaron un ascenso de albedo, y que por lo tanto arrojaron un valor negativo en la sustracción de un par de imágenes dado, fueron presentados como una clase aparte, la que en todos los casos no superó el $5 \%$ del total de la superficie del glaciar.

\section{RESULTADOS}

\section{COMPORTAMIENTO TEMPORAL DEL ALBEDO EN EL GLACIAR OLIVARES ALFA}

La Figura 1 muestra los histogramas de albedo para el glaciar Olivares Alfa por año. Puede apreciarse la progresiva constricción de las frecuencias de valores a lo largo del período de interés, pasando de un promedio de 0,43 en 1990 a 0,26 en 2017, y reduciendo sus máximos de $\sim 0,4$ a $\sim 0,7$, respectivamente. El albedo promedio en 1996 en tanto, correspondió a 0,34.
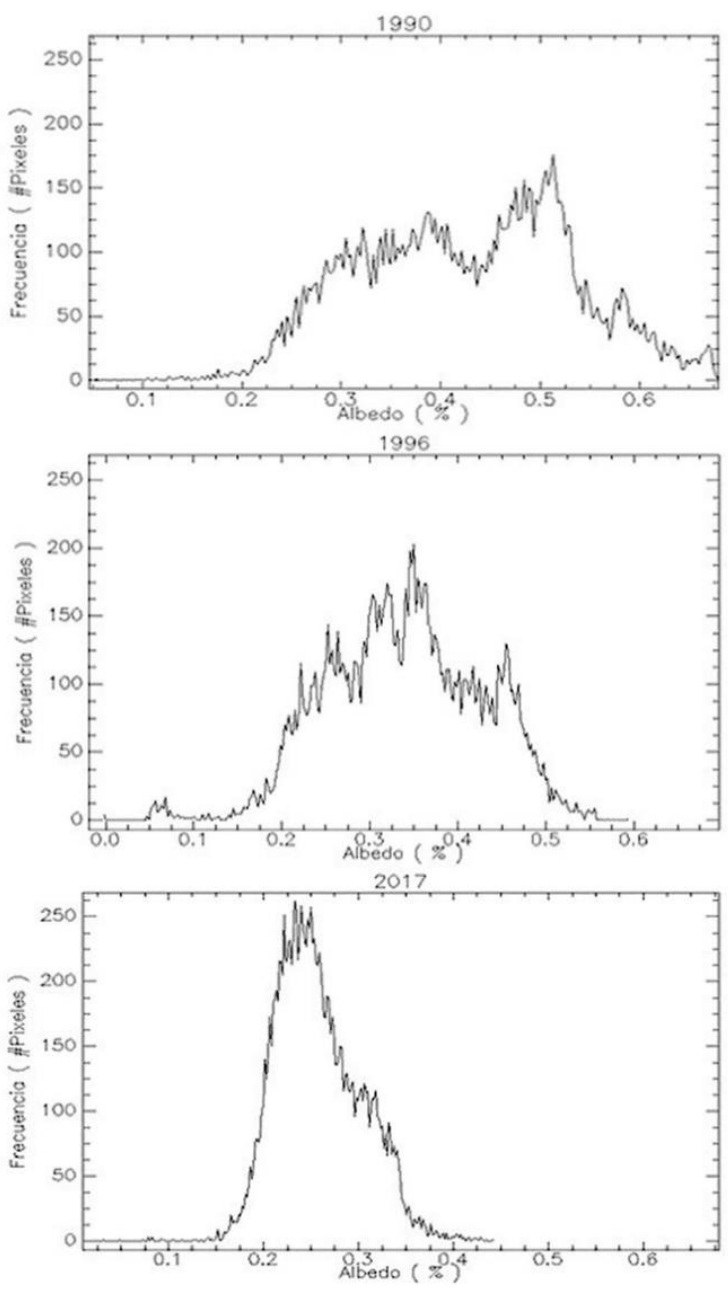

Figura 2. Histograma de los valores de albedo para el glaciar Alfa en enero de 1990, 1996 y 2017. Fuente: Elaboración Propia.

3.2. Comportamiento temporal del albedo en el glaciar Olivares Beta

En este caso también se puede observar como los histogramas de albedo agruparon sus frecuencias en torno a valores progresivamente menores a lo largo del período de interés (Figura 2), pasando de un promedio de 0,48 en 1990 a 0,39 en 2017, y de un máximo de $\sim 0,7$ a $\sim 0,49$, respectivamente. El albedo promedio en 1996 en tanto, correspondió a 0,39 . 

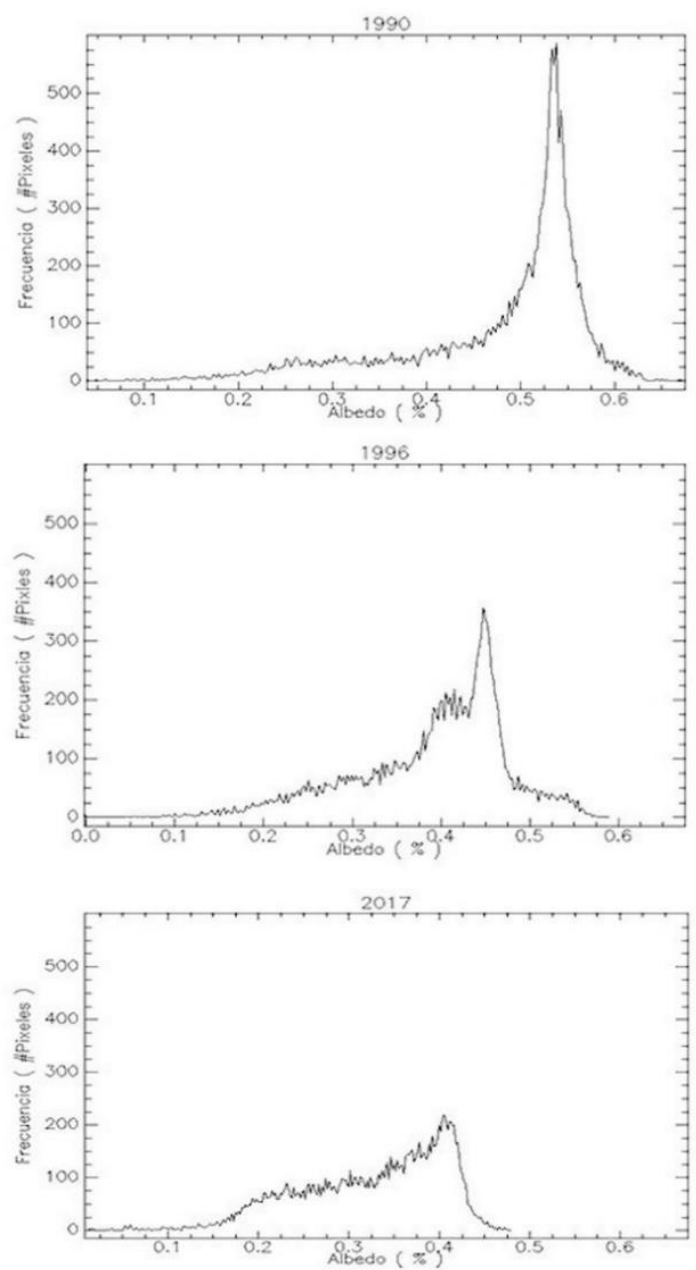

Figura 3. Histograma de los valores de albedo para el glaciar Beta en enero de 1990, 1996 y 2017. Fuente: Elaboración Propia.

\section{COMPORTAMIENTO TEMPORAL DEL ALBEDO EN EL GLACIAR OLIVARES GAMA}

De forma similar a los casos anteriores, los histogramas de albedo de los tres años de interés de este glaciar mostraron una clara tendencia a agrupar sus frecuencias en torno a valores progresivamente más bajos (Figura 3), pasando de un promedio de 0,45 en 1990 a 0,33 en 2017, y de un máximo de $\sim 0,7$ a $\sim 0,5$, respectivamente. El albedo promedio en 1996 en tanto, correspondió a 0,38 .
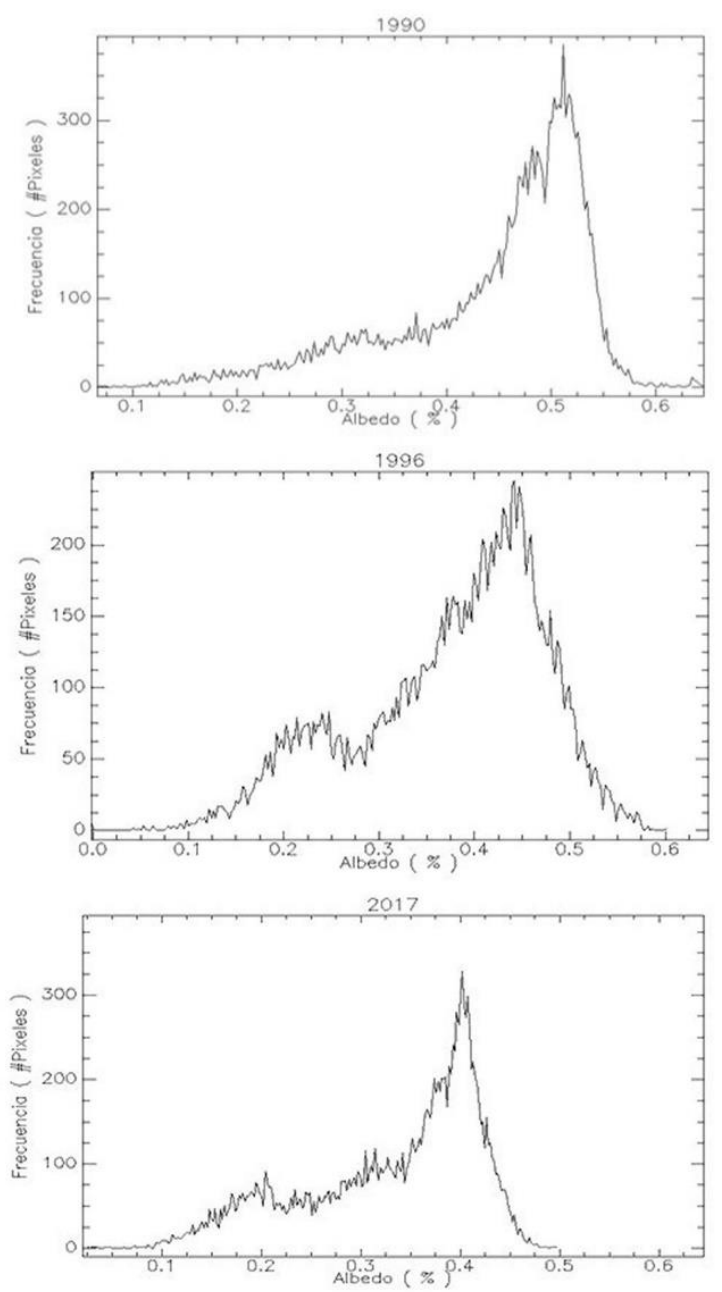

Figura 4. Histograma de los valores de albedo para el glaciar Gama en Enero de 1990, 1996 y 2017. Fuente: Elaboración Propia.

Tabla 2. Tasas de decrecimiento (\%) de albedo para los glaciares Olivares Alfa, Beta y Gama en los períodos de interés. Fuente: Elaboración Propia.

\begin{tabular}{llll}
\hline Período & $\begin{array}{l}\text { Olivares } \\
\text { Alfa }\end{array}$ & $\begin{array}{l}\text { Olivares } \\
\text { Beta }\end{array}$ & $\begin{array}{l}\text { Olivares } \\
\text { Gama }\end{array}$ \\
\hline $\begin{array}{l}1990- \\
1996\end{array}$ & $-3,3$ & $-2,92$ & $-2,39$ \\
\hline $1996-$ & $-1,21$ & $-0,76$ & -0.64 \\
2017 & & $-1,33$ & -1.1 \\
\hline $1990-$ & $-1,78$ & & \\
2017 & & & \\
\hline
\end{tabular}

Las tasas de decrecimiento de los glaciares Olivares disminuyeron entre 1996-2017 (Tabla 2), 
siendo en todos los períodos algo más altas en el Alfa.

\section{DIFERENCIAS ESPACIO-TEMPORALES DE ALBEDO PARA EL GLACIAR OLIVARES ALFA}

La Tabla 3 muestra que el albedo del glaciar Olivares Alfa experimentó una disminución promedio de 0,17 entre 1990 y 2017. Tal disminución fue algo menor en los períodos 1990 y $1996(0,09)$, y 1996 y $2017(0,08)$. Las zonas de ablación y acumulación presentaron una similar disminución promedio entre 1990 y 1996. En los períodos restantes la zona de acumulación exhibió mayores promedios de decrecimiento del albedo.

\begin{tabular}{cccc}
\hline \multirow{2}{*}{$\begin{array}{c}\text { Años } \\
\text { comparados }\end{array}$} & Zona del & \multicolumn{2}{c}{ Diferencial de albedo } \\
\cline { 3 - 4 } & glaciar & Promedio & $\begin{array}{c}\text { Desviación } \\
\text { estándar }\end{array}$ \\
\hline \multirow{2}{*}{$1990-1996$} & Acumulación & 0,08 & 0,08 \\
& Ablación & 0,09 & 0,05 \\
& Total & 0,09 & 0,07 \\
$1996-2017$ & Acumulación & 0,11 & 0,07 \\
& Ablación & 0,05 & 0,05 \\
& Total & 0,08 & 0,07 \\
$1990-2017$ & Acumulación & 0,19 & 0,09 \\
& Ablación & 0,15 & 0,07 \\
& Total & 0,17 & 0,08 \\
\hline
\end{tabular}

Tabla 3. Diferencias de albedo en el glaciar Olivares Alfa entre Enero de 1990, 1996 y 2017. Fuente: Elaboración Propia.

La Figura 5 permite observar las variaciones espaciales de albedo del glaciar Olivares Alfa entre 1990 y 2017. La primera clase ( $\leq 0)$ muestra aquellas superficies que presentaron un incremento de la variable. Es posible apreciar que la clase que representa el menor decrecimiento de la variable (azul), tendió a distribuirse hacia las morrenas situadas en la lengua y bordes del glaciar, en tanto que las clases restantes ocuparon zonas más bien cubiertas de hielo.

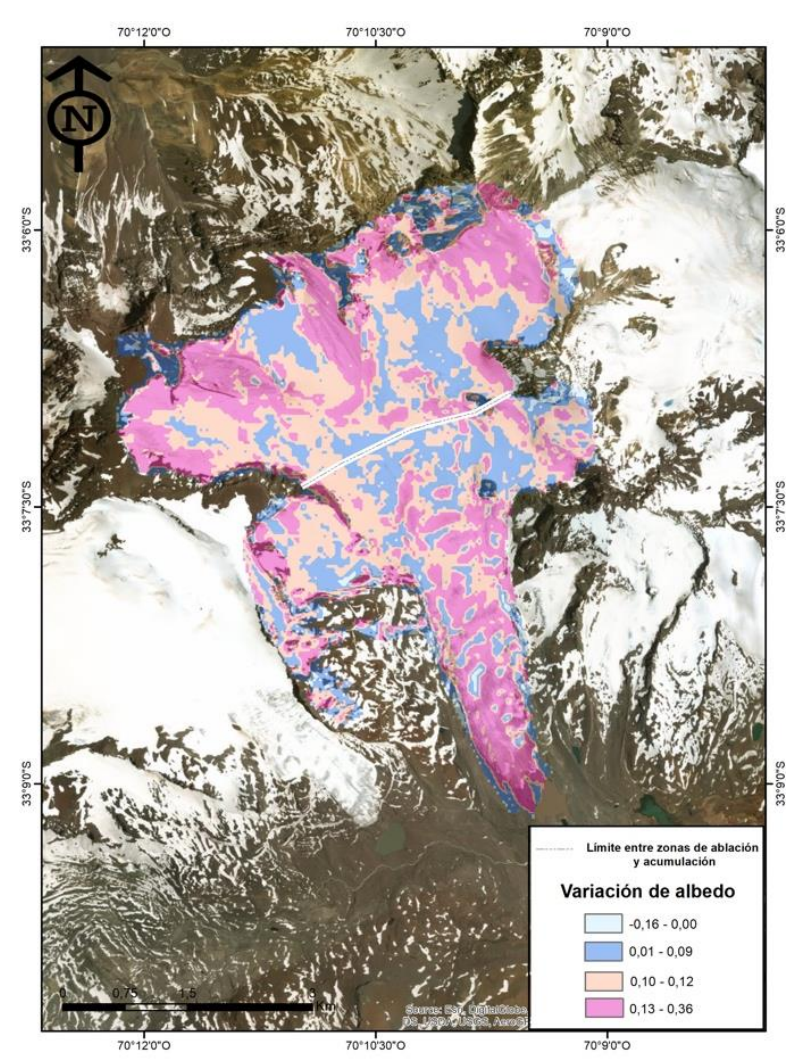

Figura 5. Variación de albedo entre los años 1990 - 2017 para el glaciar Olivares Alfa. La primera clase corresponde a superficies que aumentaron su albedo en el período de interés. Fuente: Elaboración Propia.

\section{DIFERENCIAS ESPACIO-TEMPORALES DE ALBEDO PARA EL GLACIAR BETA}

El albedo del glaciar Olivares Beta experimentó una disminución promedio de 0,15 entre 1990 y 2017 (Tabla 4). Tal disminución fue mayor entre 1990 y $1996(0,09)$ que entre 1996 y $2017(0,07)$. La zona de ablación en tanto, exhibió mayores decrecimientos promedio de albedo que la de acumulación en todos los períodos de interés.

Tabla 4. Diferencias de albedo en el glaciar Olivares Beta entre Enero de 1990, 1996 y 2017. Fuente: Elaboración Propia.

\begin{tabular}{cccc}
\hline \multirow{2}{*}{$\begin{array}{c}\text { Años } \\
\text { comparados }\end{array}$} & Zona del & \multicolumn{2}{c}{ Diferencial de albedo } \\
\cline { 3 - 4 } & glaciar & Promedio & $\begin{array}{c}\text { Desviación } \\
\text { estándar }\end{array}$ \\
\hline \multirow{2}{*}{$1990-1996$} & Acumulación & 0,07 & 0,04 \\
& Ablación & 0,10 & 0,07 \\
\multirow{2}{*}{$1996-2017$} & Total & 0,09 & 0,06 \\
& Acumulación & 0,06 & 0,04 \\
\hline
\end{tabular}




\begin{tabular}{cccc}
\hline & Ablación & 0,07 & 0,06 \\
& Total & 0,07 & 0,06 \\
\multirow{1}{*}{$1990-2017$} & Acumulación & 0,14 & 0,04 \\
& Ablación & 1,17 & 0,08 \\
& Total & 0,15 & 0,07 \\
\hline
\end{tabular}

Las variaciones espaciales de albedo del glaciar Olivares Beta entre 1990 y 2017 (Figura 6), permiten apreciar que si bien la clase que representa el menor descenso de la variable (azul), se distribuyó hacia los bordes del glaciar como en el caso del Olivares Alfa, también ocupó con claridad zonas englaciadas.

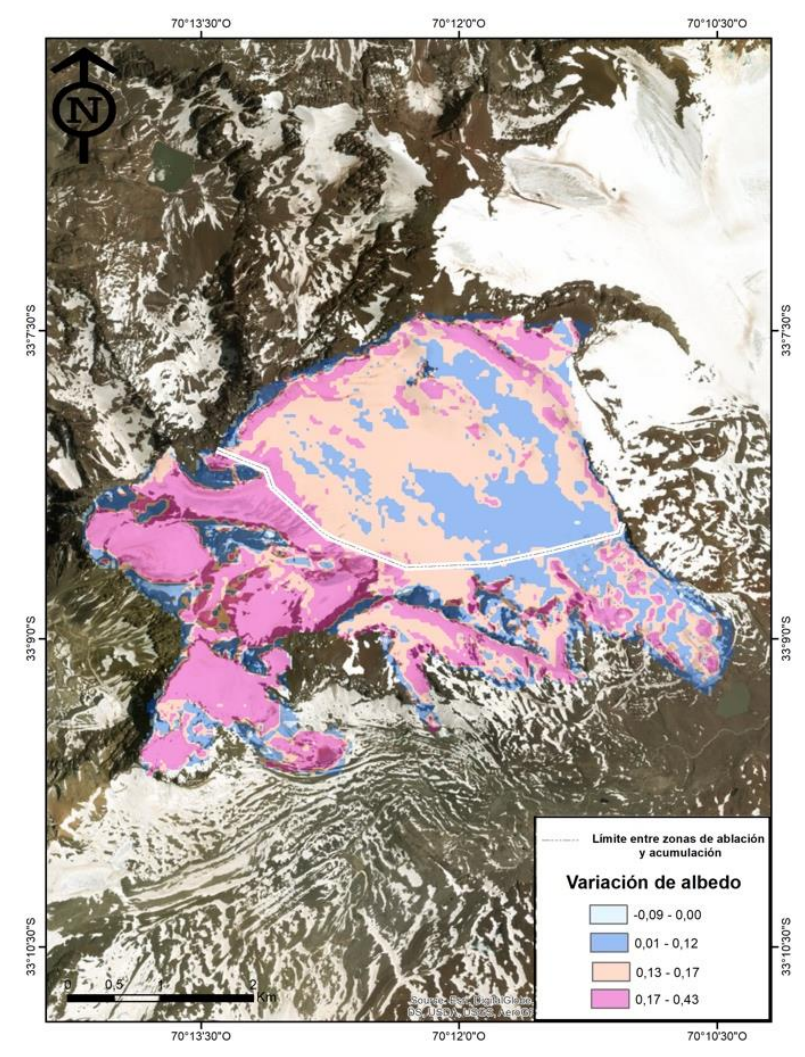

Figura 6. Variación de albedo entre los años 1990 - 2017 para el glaciar Olivares Beta. La primera clase corresponde a superficies que aumentaron su albedo en el período de interés. Fuente: Elaboración Propia.

\section{DIFERENCIAS ESPACIO-TEMPORALES DE ALBEDO PARA EL GLACIAR GAMA}

El albedo del glaciar Olivares Gama experimentó un descenso promedio de 0,11 entre 1990 y 2017 (Tabla 5). Como en el caso del glaciar Olivares
Beta, tal disminución fue mayor entre 1990 y 1996 $(0,07)$ que entre 1996 y $2017(0,04)$. Entre 1990 y 1996 la zona de ablación presentó una mayor disminución promedio de albedo que la de acumulación, sin embargo, esta situación se invirtió en el periodo 1996-2017, para luego exhibir valores equivalentes en el período 1990 y 2017.

Tabla 5. Diferencias de albedo en el glaciar Olivares Gama entre Enero de 1990, 1996 y 2017. Fuente: Elaboración Propia.

\begin{tabular}{cccc}
\hline \multirow{2}{*}{$\begin{array}{c}\text { Años } \\
\text { comparados }\end{array}$} & Zona del & \multicolumn{2}{c}{ Diferencial de albedo } \\
\cline { 3 - 4 } & glaciar & Promedio & $\begin{array}{c}\text { Desviación } \\
\text { estándar }\end{array}$ \\
\hline \multirow{2}{*}{$1990-1996$} & Acumulación & 0,05 & 0,05 \\
& Ablación & 0,09 & 0,05 \\
& Total & 0,07 & 0,06 \\
\multirow{2}{*}{$1996-2017$} & Acumulación & 0,06 & 0,05 \\
& Ablación & 0,02 & 0,05 \\
& Total & 0,04 & 0,06 \\
$1990-2017$ & Acumulación & 0,11 & 0,05 \\
& Ablación & 0,11 & 0,05 \\
& Total & 0,11 & 0,05 \\
\hline
\end{tabular}

Las variaciones espaciales de albedo del glaciar Olivares Gama entre 1990 y 2017 (Figura 6), muestran una distribución más aleatoria de sus clases que en los casos anteriores.

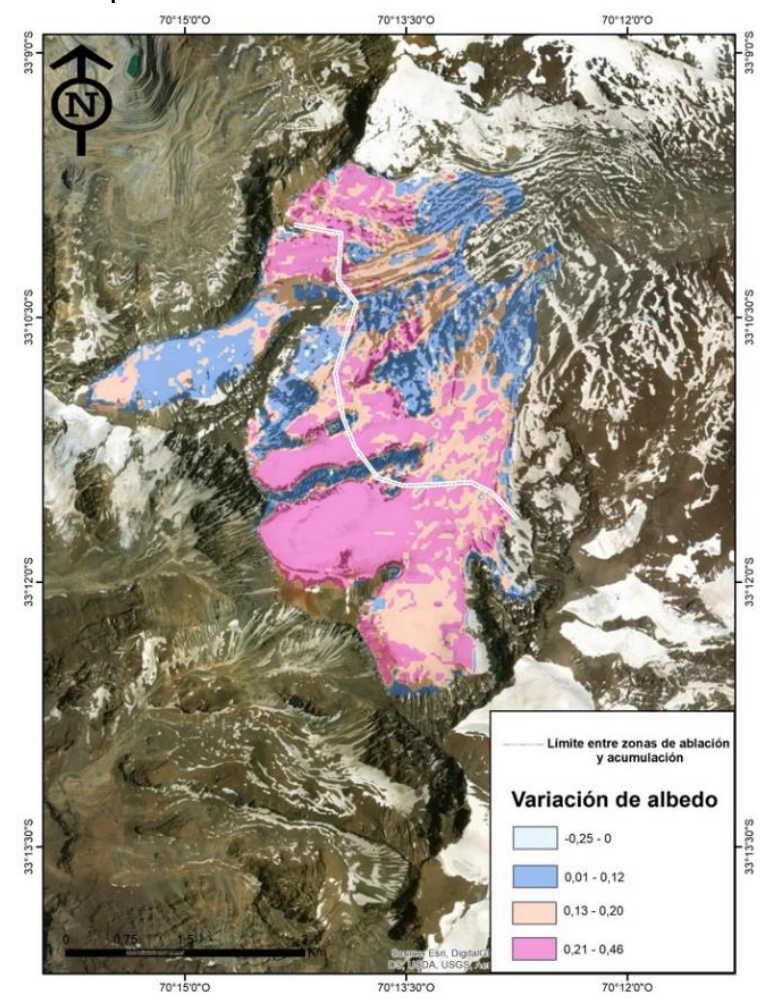

Figura 7. Variación de albedo entre los años 1990 2017 para el glaciar Olivares Gama. La primera clase corresponde a superficies que aumentaron s 43 albedo en el período de interés. Fuente: Elaboración Propia. 


\section{DISCUSIÓN Y CONCLUSIONES}

Este estudio derivó el albedo de los glaciares Olivares Alfa, Beta y Gama a partir de imágenes satelitales ópticas Landsat, con el sentido de vislumbrar sus variaciones espaciales y temporales a lo largo de tres años de interés. Los resultados revelan una clara tendencia de decrecimiento de la variable para los tres glaciares en estudio a lo largo de los años, presentando algunas diferencias en atención a sus características morfológicas.

En el glaciar Olivares Alfa, la menor disminución de albedo durante el período mapeado (1990-2017) se apreció sobre superficies compuestas predominantemente por detritos en ambos años, i.e., morrenas laterales y frontales, arrojando así un menor diferencial de la variable. En tanto, un mayor decrecimiento del albedo fue evidenciado sobre superficies cubiertas de hielo ubicadas en gran medida en las zonas de acumulación más altas, lo que podría atribuirse a la reducción del albedo producto de la mayor fusión de nieve en 2017, con la subsecuente absorción de radiación infrarroja por parte del agua en estado líquido que ello significaría (Ming et al., 2015).

En el glaciar Olivares Beta un amplio sector de su lado Oeste presentó una alta disminución de albedo en el período mapeado, debido al retroceso experimentado por la línea de hielo hacia 2017, dejando expuesto consecuentemente el lecho rocoso del circo glaciar. Por otro lado, superficies correspondientes principalmente a la parte baja de la lengua del glaciar, también exhibieron un alto descenso de la variable a causa de su ablación en 2017.

El glaciar Olivares Gama en tanto, experimentó una alta disminución de albedo para el período mapeado en su zona de ablación correspondiente a la lengua del glaciar y a depósitos morrénicos. Asimismo, la zona de acumulación mostró numerosos sectores con alto descenso del albedo, donde si bien la acumulación de nieve es alta, pudo apreciarse que muchas superficies con mayor pendiente quedaron desprovistas de nieve/neviza hacia 2017.

Los cambios de temperatura que afectan al Océano Pacífico, asociados principalmente con los fenómenos climáticos de El Niño y La Niña y otros como la Oscilación Decadal del Pacífico ( Pacific Decadal Oscillation, PDO) y los Frentes de Bloqueo Antártico (Southern Annular Mode, SAM), afectan de diversa manera al clima y la hidrología de zonas como aquella donde se ubica el área de estudio (Garreaud et al., 2009), introduciendo fluctuaciones en las precipitaciones y temperaturas que alteran y restringen analizar las tendencias temporales del albedo glaciar. A este respecto, ha sido destacado que la alta presencia de años Niño durante la primera década del siglo XXI provocó un exceso de precipitación y con ello un aumento temporal en la masa de los glaciares de Los Andes Centrales de Colombia (Ramírez y Jaramillo, 2009), lo que sugiere cautela al momento de seleccionar fechas de estudio para propósitos como el de este trabajo. Numerosos estudios han demostrado la relación existente entre reducción del albedo y perdida del hielo glaciar. Así lo confirman mediciones de albedo derivadas desde imágenes MODIS en glaciares del Himalaya (Ming et al., 2015) y desde imágenes Landsat en el glaciar de la Sierra Nevada Nevada del Cucuy, Colombia, (Herrera y Ruiz, 2009), así como mediciones de albedo hechas con piranómetros en los glaciares Toro 1 y Guanaco, ubicados en Los Andes semiáridos de Chile (Abermann et al., 2014). Lo anterior sugiere la importancia de incluir mediciones de albedo como las aquí expuestas en los balances de masa de estos y otros glaciares del país insertos en cuencas de alto valor económico y ambiental. Ello permitiría cuantificar los efectos que podrían tener los decrecimientos de dicha variable en el volumen de hielo y su relación con la variabilidad climática inducida por el calentamiento y cambio climático global.

\section{REFERENCIAS}

Abermann, J., Kinnard, C., Macdonell, S. 2014. Albedo variations and the impact of clouds on glaciers in the Chilean semi-arid Andes. Journal of Glaciology, 60(219): 183-191.

Climate prediction center. 2018. Cold and warm episodes by season. Climate Prediction Center, NOAA, EE.UU. [en línea] [fecha de consulta: 21 Junio de 2018]. Disponible en:

http://origin.cpc.ncep.noaa.gov/products/analysis monitoring/ensostuff/ONI v5.php

Church, J.A., Clark, P.U., Cazenave, A., Gregory, J.M., Jevrejeva, S., Levermann, A., Merrifield, M.A., Milne, G.A., Nerem, R.S., Nunn, P.D., Payne, A.J., Pfeffer, W.T., Stammer, D., Unnikrishnan, A.S. 2013: Sea level change. In: Stocker, T.F., Qin, D., Plattner, G.-K., Tignor, M., Allen, S.K., Boschung, J., Nauels, A., Xia, Y., Bex, V., Midgley P.M. (eds.): Climate Change 2013: The Physical Science Basis. 
Contribution of Working Group I to the Fifth Assessment Report of the Intergovernmental Panel on Climate Change. United Kingdom and New York, NY, USA: Cambridge University Press, Cambridge, pp. 1137-1216.

DGA (Dirección General de Aguas). 2018. Estadística Hidrológica en Línea. Dirección General de Aguas, Ministerio de Obras Públicas, Chile [en línea] [fecha de consulta: 21 Junio de 2018]. Disponible en:

http://snia.dga.cl/BNAConsultas/reportes

DGA (Dirección General de Aguas). 2018. Inventario de Glaciares. Dirección General de Aguas, Ministerio de Obras Públicas, Chile [en línea] [fecha de consulta: 21 Junio de 2018]. Disponible en:

http://www.dga.cl/productosyservicios/mapas/Pagi nas/default.aspx\#cuatro

Di Mauro, B., Julitta, T., Colombo, R. 2016. Glacier albedo decrease in the European Alps: potential causes and links with mass balances. Geophysical Research Abstracts, Vol. 18. EGU General Assembly 2016, 17-22 April. Vienna, Austria.

Garreaud, R.D., Vuille, M., Compagnucci, R., Marengo, J. 2009. Present-day south american climate. Palaeogeography, Palaeoclimatology, Palaeoecology, 281(3-4): 180-195.

Herrera, G., Ruiz, J. 2009. Retroceso glaciar en la Sierra Nevada del Cocuy, Boyacá-Colombia, 19862007. Perspectiva Geográfica, 1(13): 27-36.

Leiva, S. 2014. Por qué necesitamos una Ley de Protección de Glaciares. Santiago: Greenpeace en Chile, $28 \mathrm{pp}$.

Liang, S. 2000. Narrowband to broadband conversions of land surface albedo, I Algorithms. Remote Sensing of Environment, 76: 213-238.

Liang, S., LI, X., WANG, J. 2012. Advanced Remote Sensing. London: Academic Press, 799 pp.

Ming, J., Wang, Y., Du, Z., Zhang, T., Guo, W., Xiao, C., Xu, X., Ding, M., Zhang, D., Yang, W. 2015. Widespread albedo decreasing and induced melting of Himalayan snow and ice in the Early $21^{\text {st }}$ Century. PLoS ONE, 10(6): e0126235.
NASA (National Aeronautics And Space Administration). 2007. The Top of the Atmosphere. NASA Earth Observatory [en línea] [fecha de consulta: 29 Mayo de 2018]. Disponible en: https://earthobservatory.nasa.gov/IOTD/view.php?i $\mathrm{d}=7373 \&$ eocn=image\&eoci=related_image

NASA (National Aeronautics And Space Administration). 2014. Measuring Earth Albedo. NASA Earth Observatory [en línea] [fecha de consulta: 29 Mayo de 2018]. Disponible en: https://earthobservatory.nasa.gov/IOTD/view.php?i $d=84499$

Nieto, J., Carpintero, Ó., Miguel, L.J. 2018. Less than $2^{\circ} \mathrm{C}$ ? An Economic-Environmental Evaluation of the Paris Agreement. Ecological Economics, 146: 69-84.

Pistone, K., Eisenman, I., Ramanathan, V. 2014. Observational determination of albedo decrease. Proceedings of the National Academy of Sciences of the United States of America, 111(9): 3322-3326.

Ramírez, B., Jaramillo R. 2009. Relación entre el índice oceánico de El Niño y la lluvia, en la región andina central de Colombia. Cenicafé, 60(2): 161172.

Stephens, G.L., O'brien, D., Webster, P.J., Pilewski, P., Kato, S., LI, J-L. 2015. The albedo of Earth. Review of Geophysics, 53(1): 141-163.

Strahler, S. 2013. Introducing Physical Geography. New York: John Wiley \& Sons Inc., 656 pp. 